\title{
Human Resource Management Practices and Teachers' Performance in Universal Primary Education Schools of Kyankwanzi District, Uganda
}

\author{
Ibrahim Kabuuka \\ School of Graduate Studies, Team University (Uganda)
}

\begin{abstract}
This study examined the relationship between Human Resource Management (HRM) Practices and Teachers' Performance in Universal Primary Education Schools of Kyankwanzi District. The study was guided by Herzberg's Two Factors Theory of motivation (1959). The study adopted a cross sectional survey applying both quantitative and qualitative research methods. A total of 125 respondents comprising head teachers, teachers and District Education Officer participated in the study. Data was collected through questionnaire administration and key informant interviews. The collected data were analysed descriptively using SPSS $®$ computer software version 21 . The study findings concluded that, training is generally low in UPE schools. As a result, pupils in UPE schools perform poorly compared to those in private schools. The study also concluded that rewards are generally unsatisfactory for teachers. This does not only negatively affect performance of teachers but pupils as well which is why UPE schools are outperformed by private schools. It was also concluded that resourcing practices were not effectively managed. Many UPE schools had poor screening mechanisms of job applicants and ended up hiring less qualified teachers. The study recommended that: There is need for Ministry of Education to effectively implement the National Teacher Policy teacher designed to professionalize teachers, develop standards and improve the development, management, and utilization of teachers in Uganda; There is need for district local governments in collaboration with the central government especially ministry of finance to consider introducing bonus and allowance schemes for all teachers under UPE program to motivate them; There is need for school head teachers to directly have an input in the recruitment process because they understand well the kind of teachers they need
\end{abstract}

Keywords: Human Resource Management, Teachers' Performance

DOI: $10.7176 / \mathrm{JEP} / 13-2-03$

Publication date: January $31^{\text {st }} 2022$

\subsection{Introduction}

Development of human resource practices occurred nearly a century ago (Anthony et al, 2006). As a result of these studies, the social side of workers was realized by managers and the effect of social factors such as culture, job content, attitude and financial rewards on the performance was understood. This era focused more on the total organization and less on the individual. Globally, Human Resource Management (HRM) is concerned with satisfying employees' work-related needs and dealing with their problems (Torrington \& Hall, 2011). This forced managers to develop rules, regulations and procedures to control the workers. Some of the regulations required an increase in job specialization, which led to boring, monotonous jobs (Anthony et al, 2006). According to Mathias (1999), scientific management effect on workers were seen as a part of a machine without considering that they were social human beings and that all jobs were broken into specific tasks

In Africa, many employers hardly train, develop, reward, and compensate their employees leading to low performance outcomes (Kamoche, 2012). Much more attention has previously evolved around economics and foreign trade, perhaps reflecting the more dominant imperatives for a continent in which macroeconomic challenges tend to over-shadow the dynamics of managing organizations (Kamoche, 2012). In addition, the debate about management in Africa gets complicated by the complexities and diversity of this continent and its people.

In Uganda, the inadequate application of HRM practices in public primary schools has led to teacher disengagement. According to Rwakakamba (2011) many employers of different organization have not put into practice the different human resource practices like training, development, compensations and rewards and this has made very many employees not to perform to their required standards. Rwakakamba (2011) asserts that in terms of human resources, family members constitute the main source of labor in order to avoid the costs that come with formally and fully fledged human resource practice in their business, which has led to increased acceptable Grades. According to Gladys et al., (2016), many pupils do not perform to their expectations due to the inadequate human resource management practices like recruitment and selection, training and development and performance management that are not properly implemented by those in charge which has led to teacher disengagement as many teachers report late to work, leave early, attend irregularly, get alternative work elsewhere and even engage in regular strike actions as a way of resenting poor treatment from the school management which have resulted into poor performance by the teachers hence leading to poor grades by the pupils. Therefore, this 
study focused on the possibilities of human resource management practices as a way of creating dynamics and progressive techniques of teacher performance in Universal Primary Education schools of Kyankwanzi District in Uganda.

The Ministry of Public Service, (2016) and Ministry of Education and Sports (2011) recommend that for good performance of human resource, there is need to put into consideration the different humans resource practices like training of employees, awarding rewards and compensation packages and proper recruiting procedures be followed, so as to portray good performance of both the workers in various organizations/institutions. However, what is happening today is inadequate in that many institutions of learning do not follow the guidelines being emphasized as far as putting in practice the emphasis of human resource management practices such as training, compensation, proper recruitment procedures and better rewards to the staff, which has contributed to poor teacher performance in primary schools. These findings were evidenced from the summary of the Ministry of Education and Sports sector annual performance report for financial year 2013/2014 were over 12700 teachers were leaving public service for greener pastures annually (Kagolo, 2014). This is also seen in the performance of Greater Kyankwanzi Sub County UPE 2019 examination results from where the district was the $61^{\text {st }}$ in the country with only 194 students with first grade out of the total 3304 students registering only $5.87 \%$ pass with private schools like Kayomba Memorial primary school which have better human resource management practices in place registering majority of the first grades whereas some Universal primary education schools like Banda primary school, Rwomujubwe primary school, Kayanja Army primary school, Kayanja community primary school Rwengeju primary school and Kasejjere primary school with no first grade and poorest grades as a result of both poor infrastructure and bad human resource management practices (District Education Officer, 2020).

Kagolo (2014) asserts that teacher absenteeism in rural areas in Uganda stood at 35\% and that it's the highest in the world, with Ugandan teachers missing two days of work in a week, which is a financial loss to the government and its development partners since teachers are paid on monthly basis. In 2014 over 12700 teachers were leaving public service for greener pastures annually (Kagolo, 2014). It is against this background that the study investigated HRM practices and teacher performance under UPE schools in Kyankwanzi district.

\subsection{Problem Statement.}

Although the Ministry of Education and Sports (2011) and Ministry of Public service (2016) in Uganda recommend emphasis on the use of human resource management practices for better teacher performance, the human resource managers to an extent have not followed this directive. In that there is inadequate restructuring of primary teachers with a wage bill provision, improper deployment of primary school teachers across primary schools. This is seen in Kamoche (2017) report who asserts that Organizations in Uganda adopt reactive approach to the hostilities in the environment thereby neglecting the knowhow and expertise that Human Resource Management practices brings to the table and that are important towards the performance of teachers in UPE schools.

This has resulted into little attention on the emphasis of human resource management practices including teacher training, rewards, and recruitment which has resulted into absenteeism, little adherence to the school time table and increased failures to cover the syllabi thus affecting the teachers' performance. This is in support with what Kagolo, (2014) and Nkaada,(2014) who asserted that there is underperformance and repeating of classes in public primary schools as a result of improper effective teaching. Therefore, the study investigated the extent to which human resource management practices do influence teacher performance of Universal Primary schools Kyankwanzi District in Uganda.

\subsection{Objectives of the Study}

The study was guided by the following objectives.

i. To investigate how training influences teachers' performance in UPE schools of greater Kyankwanzi Sub County, Kyankwanzi District.

ii. To examine whether rewards influence performance teachers' performance in UPE schools of greater Kyankwanzi Sub County, Kyankwanzi District.

iii. To establish how resourcing practices enhance teachers' performance in UPE schools of greater Kyankwanzi Sub County, Kyankwanzi District.

\subsection{Research questions}

The research question was guided by the following questions:

i. How does training influence teachers' performance in UPE schools of greater Kyankwanzi Sub County, Kyankwanzi District?

ii. How do rewards influence teachers' performance in UPE schools of greater Kyankwanzi Sub County, Kyankwanzi District?

iii. How do resourcing practices enhance teachers' performance in UPE schools of greater Kyankwanzi 
Sub County, Kyankwanzi District?

\subsection{Literature Review}

The study is grounded on the Two Factor Theory advanced by Frederick Herzberg, a behavioral scientist in 1959 . Herzberg et al. (1959) proposed a two factor theory or the motivator-hygiene theory. According to this theory, there are some job factors that result in satisfaction while there are other job factors that prevent dissatisfaction. The opposite of "Satisfaction" is "No satisfaction" and the opposite of "Dissatisfaction" is "No Dissatisfaction". Herzberg et al. (1959) classified these job factors into hygiene and motivator factors. Hygiene factors are those job factors which are essential for existence of motivation at workplace. These do not lead to positive satisfaction for long-term. But if these factors are absent or if these factors are non-existent at workplace, then they lead to dissatisfaction. In other words, hygiene factors are those factors which when adequate/reasonable in a job, pacify the employees and do not make them dissatisfied. These factors are extrinsic to work. Herzberg's framework was relevant to the study in identifying the effect of human resource management practices in form of hygiene factors (e.g. pay, allowances and company policies) and motivators (e.g. recognition, promotion and sense of achievement) on teacher performance as a way of as a way of increasing job enrichment for employees. Many teachers have shunned government aided primary schools to private primary schools in search of better pay and satisfaction. It is therefore important for school administrators as well as government to understand how such HRM practices influence teacher performance under UPE schools

Angrist and Lavy's (2011) assessed the relationship between teacher characteristics and pupil achievement focusing on salaries, experience, and education. The results revealed a significant positive relationship between teachers' training and students' test scores. The cost-benefit analysis of the study also shows that teachers' training could provide a less costly way of improving students' grades than cutting down the class size or increasing the class hours. The way a teacher delivers knowledge/lecture is not changed by the training he/she receives. The improvement in students' performance with a trained teacher is just because ofa better grip on subject matter. The literature emphasizes student grades as the outcome of teacher training ignoring other metrics like dropout rate. This study addressed that gap by investigating the influence of teacher training on student dropout rate in UPE schools.

Wasilu (2013) examined the causes of poor attitude to work among workers of both public and private sectors organizations in Bauchi State-Nigeria. Some of the prominent findings revealed that Nigerian workers widely held view that inadequate training and development and job insecurity are the possible causes of poor attitude to work. The literature explains more on job insecurity as a precursor of poor attitude to work but does not talk about teacher participation. This study filled that gap by assessing the influence of participation on teachers' performance in UPE schools.

A study conducted by Ahmed (2012) and Anita (2014) stressed that compensation and promotional opportunities had imperative relationship with employees' retention in public sector. Moreover, the results also revealed that work environment moderates the relationships between compensation and employee retention and promotional opportunities and employee retention. They asserted that there is a significant relationship between compensations and employee performance. And that an effective human resource management strategy is to integrate performance and compensation system that enhance employee's will to work effectively and efficiently. The literature stresses employee retention but does not talk about student retention. This study addressed that gap by examining the influence of compensation programs on retention of students in UPE schools.

Katou and Budhwar (2007) assert that recruitment and selection is positively related to all organizational performance variables such as effectiveness, efficiency, innovation and quality. The literature emphasizes organizational performance rather than teacher performance. This study addressed that gap by assessing the influence of resourcing practices on performance of UPE teachers.

According to Billah and Islam, (2009) human resource management practices have significant association with employee turnover and organizational commitment. The study mainly focuses on employee turnover and organizational commitment in private organizations but does not talk about the employee selection systems. This study addressed that gap by examining employee selection systems and performance of teachers in UPE schools.

Gberevbie (2010) asserts that organizations exist to achieve goals therefore human resource is seen as one of the most crucial factors, without which the goals are as good as dead (Gberevbie, 2010). A capable workforce is required, and such a workforce can only be obtained through correct recruitment and selection. The literature focused so much on factors influencing recruitment and retention of teachers but not the recruitment procedures. This study established if recruitment and selection procedures are conducted in accordance with the public service human resource management policy of Uganda.

\subsection{Methodology}

\subsection{Research Design}

The study adopted a cross sectional survey applying for quantitative and case study for qualitative approaches. A 
cross-sectional study was best suited for this study because it allowed collection of data from many different individuals at a single point in time without influencing the variables (Lauren, 2020).

\subsection{Location of the Study}

The study was carried in six (6) of the thirteen (13) Sub-counties in Kyankwanzi district of Uganda. The study area was selected because of the deteriorating teacher performance in UPE schools (Kyankwanzi District Annual Report, 2019).

\subsection{Target Population}

The study population was 200 for the respondents in selected UPE schools in Greater Kyankwanzi District. It included 190 teachers, 6 head teachers and 1 Educational Officer. They were chosen because they were more knowledgeable about human resource management practices and teacher performance in UPE schools. The study considered six UPE schools in Kyankwanzi district. And these UPE schools were randomly selected from the six sub counties in the district.

\subsection{Sampling Technique and Sampling Size}

Krejcie and Morgan (1970) sample table was used to determine the sample size. From the study population of 200 persons, the sample of 132 was derived.

\subsection{Research Instruments}

Questionnaires were administered by the researcher to 125 teachers. The instrument was cost effective to collect data from such a large section of respondents in a limited time (Cresswell, 2013).

An interview guide was used to collect data from six (6) head teachers and one (1) District Education Officer. This instrument helped in triangulation as guided by (Mugenda \& Mugenda, 1999). It provided in-depth findings and closes the gaps left by the questionnaire.

\subsection{Validity and Reliability of Research Instrument}

In establishing the validity of the instrument, the researcher consulted the supervisors and a panel of experts who rated the instruments independently and gave advice where corrections were made before it was administered to the participants. Besides, the researcher also ascertained the instrument validity by calculating the content validity index (CVI) by dividing the total number of valid items over the total number of the items in the questionnaire using this formula.

The study used Cronbach's alpha coefficient to determine the internal consistency of the scale that was used to measure the reliability of the variables of the study. The instruments were reliable because the alpha coefficient was above 0.6 as recommended by (Cooper and Schindler 2008).

\subsection{Findings and Discussions}

The research questions were tested using the correlation analysis to establish the relationship between independent and dependent variables. Qualitative data collected through key informant interviews were analysed using thematic analysis procedures.

Objective 1: To investigate how training influences teachers' performance in UPE schools of greater Kyankwanzi Sub County, Kyankwanzi District.

Pearson correlation analysis was carried out to establish the relationship between training and teachers' performance in UPE schools of greater Kyankwanzi Sub County, Kyankwanzi District. Results are presented as follows;

Table 1: Correlations results on training and teachers' performance in UPE schools

\begin{tabular}{llll}
\hline & & Training & Teacher Perf \\
\hline Training & Pearson Correlation & 1 & $.684^{* *}$ \\
& Sig. (2-tailed) & & .000 \\
& $\mathrm{~N}$ & 125 & 125 \\
\hline Teacher Perf & Pearson Correlation & $.684^{* *}$ & 1 \\
& Sig. (2-tailed) & .000 & 125 \\
\hline
\end{tabular}

**. Correlation is significant at the 0.01 level (2-tailed).

The results show that there is a positive and a statistically significant relationship between training and teacher performance in UPE schools of greater Kyankwanzi Sub County, Kyankwanzi District $(r=.684$, Sig. p 
$=.000<0.05)$. Since the correlation is $(\mathrm{r}=.684)$, it implies that the two variables have a positive relationship, as training of teachers increases, teacher performance also increases.

This was also supported by the qualitative facts from a key informant interview from the one Head teacher who said that;

"When a teacher is trained, we expect the quality of assignments he gives to students to also be of high quality" (Head Teacher; 2021).

Another respondent said that;

"The teacher training programs encourage teachers to talk about what makes good pedagogical practice that is, the elements that need to be present for effective teaching and successful learning to take place and how these elements react." (District Education Officer, Kyankwanzi District; 2021).

Objective 2: To investigate how reward influences teachers' performance in UPE schools of greater Kyankwanzi Sub County, Kyankwanzi District.

Table 2: Correlations results on rewards and teachers' performance in UPE schools

\begin{tabular}{llll}
\hline & & Rewards & Teacher Perf \\
\hline Rewards & Pearson Correlation & 1 & $.601^{* *}$ \\
& Sig. (2-tailed) & & .000 \\
& $\mathrm{~N}$ & 125 & 125 \\
\hline Teacher Perf & Pearson Correlation & $.601^{* *}$ & 1 \\
& Sig. (2-tailed) & .000 & \\
& $\mathrm{~N}$ & 125 & 125 \\
\hline
\end{tabular}

**. Correlation is significant at the 0.01 level (2-tailed).

Table 2 showed that there is a positive and a statistically significant relationship between rewards and teacher performance in UPE schools of greater Kyankwanzi Sub County, Kyankwanzi District $(r=.601 * *$, Sig. $p$ $=.000<0.05)$. Since the correlation is $(\mathrm{r}=.601)$, it implies that the two variables have a positive relationship, as rewards increase, teacher performance also increases.

One respondent said that;

"Better payment enables teachers to encourage pupils to actively take part in the activities conducted for their benefit and to ask questions. This helps in the overall development of the child and would also increase his capability and finally his grades." (Head teacher, UPE School; 2021).

To encourage expertise in academic settings, it is critical to have award mechanisms in place which help reward the above-and-beyond efforts of teachers. Hammer et al (2010) added that recognizing excellent teachers would suggest another potential benefit: retention of exemplary instructors.

Objective 3: To examine how resourcing practices influence teachers' performance in UPE schools of greater Kyankwanzi Sub County, Kyankwanzi District.

Table 3: Correlation results on resourcing practices and teachers' performance in UPE schools

\begin{tabular}{llll}
\hline & & Resourcing Practices & Teacher Perf \\
\hline Resourcing Practices & Pearson Correlation & 1 & $.577^{* *}$ \\
& Sig. (2-tailed) & & .000 \\
& $\mathrm{~N}$ & 125 & 125 \\
\hline Teacher Perf & Pearson Correlation & $.577^{* *}$ & 1 \\
& Sig. (2-tailed) & .000 & 125 \\
\hline
\end{tabular}

**. Correlation is significant at the 0.01 level (2-tailed).

Table 3 showed that there is a positive and a statistically significant relationship between resourcing practices and teacher performance in UPE schools of greater Kyankwanzi Sub County, Kyankwanzi District ( $r=.577^{* *}$, Sig. $p$ $=.000<0.05)$. Since the correlation is $(\mathrm{r}=.577)$, it implies that the two variables have a positive relationship, as resourcing practices increase, teacher performance also increases.

This was supplemented by one of the head teachers who responded that;

"A teacher's influence, ideas, and expectations of his or her pupils' capabilities have an effect on their academic performance and achievements. Qualified teachers tend to positively influence learners by encouraging them to aim higher." (Head Teacher, UPE School; interviewed 2021).

The findings also revealed that UPE schools follow standard HR procedures of hiring and selecting teachers in order to ensure that the best performing teachers are hired. The finding is further supported by the one of the head 
teachers who added that;

"The Kyankwanzi District Education Service Commission ensures that the best candidates are sought during the selection process. They clearly specify aspects like minimum years of work experience, education background, and required minimum skills.” (Head Teacher UPE School; 2021).

\subsection{Conclusion}

The study concluded that, training is generally low in UPE schools. This means that teachers are unable to sharpen their skills to match with the current teaching demands, are less motivated to take on new tasks, have low passion and interest in their job, cannot relate well with pupils and are less empowered by their supervisors hence the low teacher performance. As a result, pupils in UPE schools perform poorly compared to those in private schools. It was also concluded that rewards are generally unsatisfactory for UPE teachers. Besides being paid low salary, delays in payment are common, there are no allowances and bonuses, job promotions and recognition are also very rare. Lastly, the study concluded that resourcing practices were less effective because many UPE schools had poor screening mechanisms of job applicants and ended up hiring less qualified teachers. Likewise, the performance of learners is negatively affected which is why private schools perform better than UPE schools.

\subsection{Recommendations}

Based on the study findings and conclusion, the following recommendations were suggested;

- There is need for Ministry of Education to effectively implement the National Teacher Policy teacher designed to professionalize teachers, develop standards and improve the development, management, and utilization of teachers in Uganda.

- There is need for Head teachers to document staff performance overtime for which appropriate training could be recommended. It should be balanced across classes, disciplines, functions and levels depending on need.

- There is need for district local governments in collaboration with the central government especially ministry of finance to consider introducing bonus and allowance schemes for all teachers under UPE program to motivate them.

- There is need for Ministry of Education to lobby for salary increment of government primary teachers. Salary is the primary motivator for many teachers. Salary should be increased to match the increased cost of living, provision of accommodation to teachers, enhancing supervision as well as offering awards for good performance.

- There is need for school head teachers to directly have an input in the recruitment process because they understand well the kind of teachers they need. The process should not only be done by the District Service Commission alone as it may not fully understand individual school needs.

- There is need for district leaders to regularly monitor teachers to ensure that performance targets are met.

\section{References}

Ahmed, I., \& Islam, T. (2011). Relationship between motivation and job satisfaction: a study of higher educational institutions. J Econ Behav Stud, 3(2), 94-100.

Angrist, J.D. \& Lavy, V. (2011). Does teacher training affect pupil learning? Evidence from matched comparisons in Jerusalem public schools. Journal of Labor Economics, 19(2):343-369

Cooper, D., \& Schindler, P. (2008). Business research methods (10th ed.). New York, McGraw-Hill/Irwin.

Creswell, J.W. (2013) Research Design Qualitative, Quantitative, and Mixed Methods Approaches. 4th Edition, SAGE Publications, Inc., London.

Gladys, S., Nicholas, Z., \& Crispen, B. (2016). Undergraduate Students' Views on Their Learning of Research Methods and Statistics (RMS) Programme: Challenges and Alternative Strategies. International Journal of Social Science Tomorrow 1 (3): 1-9.

Herzberg F., Mausner B., Synderman B. (1959). The motivation to work. NY: Wiley.

Kagolo, F. 2014. Nine Million Pupils Repeat: What happened to Automatic Promotion? The New Vision. Pp.2231.

Kamoche, K., Chizema, A., Mellahi, K. and Newenham-Kahindi, A. (2012), "New directions in the management of human resources in Africa", International Journal of Human Resource Management, Vol. 23 No. 14, pp. 2823-2834.

Katou, A. A., \& Budhwar, P. S. (2007). The effect of human resource management policies on organizational performance in Greek manufacturing firms. Thunderbird international business review, 49(1), 1-35.

Krejcie, R. V., \& Morgan, D. W. (1970). Determining sample size for research activities. Educational and Psychological Measurement, 30(3), 607-610.

Kyankwanzi District Annual Report, (2019) 
Mathis, Robert .L. and John .H. Jackson, (1999). Human Resource Management, Cincinnati, OH. South-Western College Publishing

Ministry of Education and Sports. MOES. (2011). Teachers' initiative in sub-Saharan Africa (TISSA): Teacher issues in Uganda: A diagnosis for a shared Vision on issues and the designing of a feasible, indigenous and effective teachers' policy. Kampala: Ministry of Education and Sports.

Ministry of Education and Sports (2011). Uganda Education Statistical Abstract.

Ministry of Public Service (2016). Strategic Plan 2015/2016 - 2019/2020

Mugenda, O.M. and Mugenda, A.G. (1999) Research Methods: Quantitative and Qualitative Approaches. Acts Press, Nairobi.

Rwakakamba, M. (2011). Budget Priorities and Job Creation in a Competitive Regional Market. Twaweza: The African Executive.

Torrington, D, et al. (2011). Human Resource Management. $8^{\text {th }}$ Ed. London: Prentice Hall. 